\title{
OpenFOAM Numerical Simulations with Different Lid Driven Cavity Shapes
}

César A. Cárdenas R., Carlos Andrés Collazos Morales, Juan P. Ospina, Joaquín F. Sánchez, Jelibeth Racedo-Gutiérrez, Paola Ariza-Colpas, Emiro De-la-Hoz-Franco, Ramón E. R. González

\begin{abstract}
The finite volume method have been developed to solve the Navier-Stokes equations with primitive variables and non dimensional form. This work examine the classical benchmark problem of the lid-driven cavity at a different Reynolds range ( $\operatorname{Re}=10,100,400,1000,2000,3200$ ) and several cavity geometries. The cavity configurations include square cavity, skewed cavity, trapezoidal cavity and arcshaped cavity. The flow is assumed laminar and solved in a uniform mesh. A CFD tool with its solvers (icoFoam) will be used for this study.
\end{abstract}

Keywords: Cavity, OpenFOAM, icoFoam, Vorticity, Lid-driven cavities 